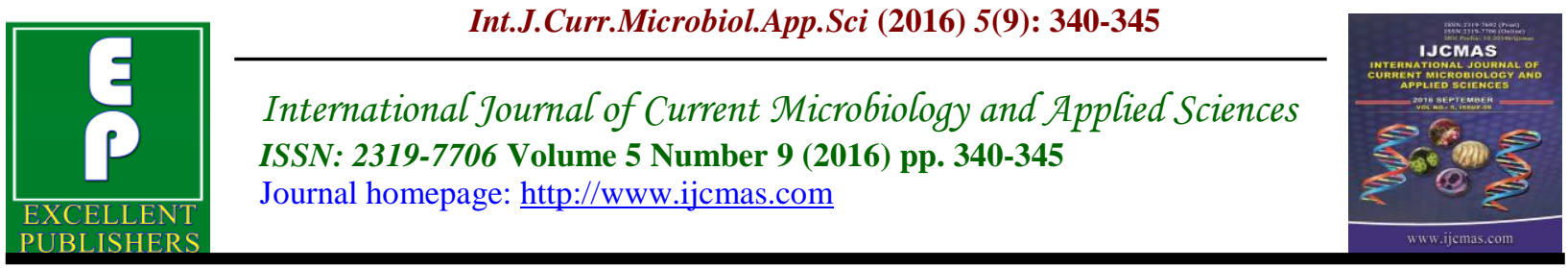

Original Research Article

http://dx.doi.org/10.20546/ijcmas.2016.509.037

\title{
A Cross Sectional Study on Health Care Waste Management among Health Care Personnel in a Tertiary Care Center, Kannur, Kerala, India
}

\author{
R. Shyamala ${ }^{1 *}$ and G. Naveen ${ }^{2}$ \\ ${ }^{1}$ Department of Microbiology, Kannur Medical College, India \\ ${ }^{2}$ Department of Microbiology, PES medical college, Kuppam, India \\ *Corresponding author
}

\begin{tabular}{l} 
Ke y w o r d s \\
Biomedical \\
waste, \\
Health care, \\
Hospital \\
Wastes. \\
\hline Article Info \\
\hline Accepted: \\
15 August 2016 \\
Available Online: \\
10 September 2016
\end{tabular}

\section{A B S T R A C T}

Hospital waste management has become a critical issue as it poses potential health risks and damage to environment. All those wastes which are generated in hospitals or during health care activities carries a higher risk for infection and injury than any other wastes. Biomedical waste are any waste that is generated during diagnosis, treatment or immunization of human beings or animals/ research act pertaining to or in the production or testing of biologicals. Thus, this study was conducted with the objective of assessing the knowledge, attitude and practice regarding biomedical waste management among healthcare personnel. A descriptive crosssectional study was done to assess the knowledge, attitude and practices regarding hospital waste management done at Kannur Medical College, Kannur during February 2016 to April 2016. Hundred health care personnel (Doctors, Nurses, Lab technicians, Management staff) working for $>3$ months was included for the study. The study instrument was a structured questionnaire having two parts, Part I comprised of age, sex, work level and experience, part II related was to knowledge, attitude and practices. Knowledge was assessed by questions related to hospital wastes, statutory bodies, waste collection, segregation, transport and disposal. Attitude questions were accredited to thinking to situations while handling hospital wastes. Practices were assessed by the questions related to the actions and contemplation of hospital rules. In our study we found appropriate knowledge $64 \%$, good attitude and practice as $88 \%, 59 \%$ respectively. Staffs had good attitude $(>80 \%)$ regarding BMW management. All our staff had relatively had good practice, best practices were given by nurses as compared to doctors and technicians.

\section{Introduction}

In past two decades waste management has become one of the most important public concern in developing countries. Hospital waste management has become a critical issue as it poses potential health risks and damage to environment.
All those wastes which are generated in hospitals or during health care activities carries a higher risk for infection and injury than any other wastes. In the process of treating and preventing diseases hazards and non-hazardous wastes are developed 
inevitably, which is a concern for public, health care workers and environment.

Biomedical waste are any waste that is generated during diagnosis, treatment or immunization of human beings or animals/ research act pertaining to or in the production or testing of biological. According to WHO reports non hazardous wastes is upto $85 \%$, hazards wastes may constitute for $10 \%$ and other wastes constitute $5 \%$. However, this is a rough estimate and it varies from region to region.

For effective waste management, Biomedical waste management(BMW) rules was given by government of India in 1998 and timely amendments done, but still health care settings fail to implement guidelines for effective disposal of biomedical wastes. The staff lacks knowledge about the transmission of hospital acquired infections caused by poor handling of healthcare waste, poor attitude of staff towards hospital regulations; inadequate training of staff on waste management and in adequate budget location are few reasons for improper management (Sanjeev et al., 2014; Mohammad Nasir Uddin et al., 2014). WHO reports in 2002 that $18-64 \%$ of health care settings in nine developing countries do not use proper biomedical waste disposal methods.

Knowledge, attitude and practices are the three important corners which make any project successful. Knowledge, being the basic criterion that allows one to earmark between the right and the wrong, is a mixture of comprehension, experience, discernment and skill. Attitude accredits to thinking towards a proper situation. Practice means contemplation of rules and knowledge that lead to action. Thus, a right knowledge, a positive attitude and a good practice are imperative to guide and serve the patients (Vanesh Mathur et al., 2011; Uma et al., 2014). In recent past there is increasing awareness regarding appropriate waste management and training of staff in all aspects and considerably improved budget locations by the health centers (BMW rules, 2015). Study shows there is $50 \%$ knowledge among technical staffs in hospitals regarding waste management (Vetrivel Chezian Sengodan et al., 2014).

Thus, this study was conducted with the objective of assessing the knowledge, attitude and practice regarding biomedical waste management among healthcare personnel.

\section{Materials and Methods}

This is a descriptive cross-sectional study to assess the knowledge, attitude and practices regarding hospital waste management done at Kannur Medical College, Kannur during February 2016 to April 2016. Hundred health care personnel (Doctors, Nurses, Lab technicians, Management staff) working for $>3$ months was included for the study. The study instrument was a structured questionnaire having two parts, Part I comprised of age, sex, work level and experience, part II related was to knowledge, attitude and practices. Knowledge was assessed by 13 questions related to hospital wastes, statutory bodies, waste collection, segregation, transport and disposal. Attitude questions were accredited to thinking to situations while handling hospital wastes. Practices were assessed by the questions related to the actions and contemplation of hospital rules. Study was reviewed from the Institutional ethical board. After telling the importance of the study, questionnaire was distributed to staffs at their work station and collected immediately after answering, checked for complete response. After completion of the data collection, 
sensitization program was organized to discuss the appropriate methods for waste disposal.

\section{Important definitions used in the study are:}

Biomedical wastes: Biomedical waste means any waste that is generated during diagnosis, treatment or immunization of human beings or animals/ research act pertaining to or in the production or testing of biologicals.

Health care workers: All staff working in our hospital for $>3$ months.

\section{Knowledge}

In this study knowledge means information about hospital waste, classification of hospital waste, generation process, segregation process, collection procedure, transportation, incineration, dumping procedure, and safe disposal.

Best possible answers/ appropriate answer and amendments were considered according to the BMW rules 2015 .

\section{Data analysis}

Incomplete questionnaires were excluded. Data was double checked for completeness and cleaned for missed values. Three variables which were dichotomous i.e. Knowledge (Appropriate/ In-Appropriate) Attitude (Positive/Negative) and Practice (Safe/Un-Safe) were used as outcome variables. Descriptive data will be analyzed with Chi square test and Fisher's Exact test. $\mathrm{P}$ value $<0.05$ will be considered as statistically significant. Logistic regression will be used to calculate the independent odds ratio (OR) for professional risk assessment.

\section{Results and Discussion}

In the present study, participants were in the age group of 18-70 years, 66 were females and 34 were males. Majority of the study population falls in the range of 24-40 years. Among the group 20 were doctors, 30 nurses, 48 technicians and 2 administrative people were stratified for the study. Forty people had the work experience of $>4$ years, 36 people was working for less than a year (>3months) and 24 people were working between 1-4 years. Trained staff among study population was 68 and untrained staffs were 42.

In our study we found appropriate knowledge $64 \%$, good attitude and practice as $88 \%, 59 \%$ respectively. As shown in the table1, Doctors had better attitude as compared to others and nurses had better practices than any other.

In the present study, $82 \%$ of the people knew the complete definition of biomedical wastes. But only $34 \%$ of the people knew that $\mathrm{BMW}$ is under state pollution control board. $10 \%$ of the study group didn't had the knowledge that administrator has to take necessary steps to ensure the BMW is handled without any adverse effects. $30 \%$ of the staff knew generally infectious wastes contribute to $10-15 \%$. $80 \%$ of the people knew wastes have to be segregated at the point of generation. $20 \%$ of the staff could label all the equipments related to BMW management. 54\% of the people knew chlorinated bags shouldn't be used for waste segregation. $90 \%$ of the people knew the signage of biohazard. $72 \%$ of the people knew BMW should be buried away from the urban area. $30 \%$ people know the combustion efficiency of an incinerator. $32 \%$ had the knowledge of permissible bioassay test. 
Staffs had good attitude (>80\%) regarding BMW management.

A. Do you agree Segregation of waste has to be done at point of generation?

B. Biomedical wastes should be segregated into colour coded bags/ containers.

C. Do you agree that it is the duty of all health care workers to take all necessary steps to ensure that the biomedical waste collected from the occupier is transported, handled, stored, treated and disposed of without any adverse effect to the human health and environment?

D. Mutilation/ Shredding must be done to prevent unauthorized reuse.

E. Do you feel sharp injuries/ accidents has to be reported to concerned persons.
Correct $(\%)$ Incorrect

80

20

90

10

90

10

84

16

94

6
Anything above $60 \%$ was considered as good practice. All our staff had relatively had good practice, best practices were given by nurses as compared to doctors and technicians. And $2 \%$ of the people were not confident in handling hospital wastes. We found that these staffs were untrained and new staff.

$72 \%$ people said white instead of blue for sharp disposal, according to the previous protocols.

Regarding pretreatment of sharps with disinfectant $94 \%$ staffs practiced pretreatment and $66 \%$ people identified all sharps which required disinfection before disposal. $76 \%$ of people never used chlorinated bags for incineration. $50 \%$ of the staff knew/ practiced appropriate colour bags for incineration.
$28 \%$ people had sharp injury. $42 \%$ of people reported to concerned people. $92 \%$ people knew they are supposed to get immunized for hepatitis B and $88 \%$ of our staff were immunized. $88 \%$ people used protective measures to prevent health hazards.

In many countries, knowledge about the potential for harm from health-care wastes has now become more prominent to governments, medical practitioners and civil society. Increasingly, managers and medical staff are expected to take more responsibility for the wastes they produce from their medical care and related activities. The indiscriminate and erratic handling and disposal of waste within health-care facilities is now widely recognized as a source of avoidable infection, and is synonymous with public perception of poor standards of health care.

Table.1 KAP among study group

\begin{tabular}{|l|l|l|l|}
\hline & Knowledge & Attitude & Practice \\
\hline Doctor & $65 \%$ & $96 \%$ & $65.84 \%$ \\
\hline Nurses & 64.4 & 90.66 & 71.95 \\
\hline Technicians & 57.7 & 82.5 & 62.2 \\
\hline Management & 58.3 & 100 & 83.34 \\
\hline
\end{tabular}


Table.2 Waste segregation using colour coded bags

\begin{tabular}{|l|l|l|}
\hline Colour coded bags & Correct & Wrong \\
\hline Yellow & 92 & 08 \\
\hline Red & 76 & 24 \\
\hline White & 52 & 48 \\
\hline Blue & 38 & 62 \\
\hline
\end{tabular}

Knowledge about biomedical waste management rules among the technically qualified personnel like the doctors, nurses, and laboratory staff is good; this was similar to the findings from other studies (Umar et al., 2014). Similarly, knowledge about color coding of containers, and waste segregation which itself is probably the most important pivotal point and crucial for further waste management, was also found to be better among the nurses. Training of both the technical staff and the nontechnical staff is critical for the proper and appropriate management of biomedical waste. The practice of reporting of injuries resulting from improperly disposed biomedical waste was found to be low among the technical staff and was found to be completely absent among the staffs. Sein et al., in their study reported that among doctors and nurses, only $37 \%$ reported that they ever suffered needle stick injury. Low reporting of injuries may be attributed to the fact that most of the doctors and other technical and nontechnical staff are unaware about a formal system of injury reporting which should be established within all the health facilities.

\section{Limitations}

Housekeeping staffs were not considered in this study. As they were under training during our study period. Further study has to be evaluated with considering the housekeeping staffs.

To conclude, lack of proper and complete knowledge about biomedical waste management impacts practices of appropriate waste disposal.

\section{References}

BMW Rules. 2015. Govt of India.

Mohammad Nasir Uddin, Mohammad Rashedul Islam, Khadiza, Y. et al. 2014. Knowledge on Hospital Waste Management among Senior Staff Nurses Working in a Selected Medical College Hospital of Bangladesh. J. Waste Manage.

Muluken Azage Yenesew, Haimanot Gebrehiwot Moges, Solomon Meseret Woldeyohannes et al. 2012. A cross sectional study on factors associated with risk perception of healthcare workers toward healthcare waste management in health care facilities of Gondar Town, Northwest Ethiopia. Int. J. Infect. Control, $\operatorname{vol} 8(3)$.

Sanjeev, R., Suneesh Kuruvilla, Subramaniam, R., et al. 2014. Knowledge, attitude, and practices about biomedical waste management among dental healthcare personnel in dental colleges in Kothamangalam: A cross-sectional study. Health Sci., 1(3): JS001I.

Umar, A.B., Rphn, Mohammed Nura Yahaya, et al. 2014. Hospital Waste Management Practices: A Case Study of Primary Health Care Centers, In Fagge Local Government Area, Kano State. J. Nursing and Health Sci., 
Volume 3, Issue 6 Ver. II (Nov.-Dec. 2014), PP 26-33.

Vanesh Mathur, S., Dwivedi, M.A., Hassan, et al. 2011. Knowledge, Attitude, and Practices about Biomedical Waste Management among Healthcare Personnel: A Cross-sectional Study. Indian J. Community Med., /Vol 36/Issue 2.
Vetrivel Chezian Sengodan, Amruth, K.H. et al. 2014. Knowledge attitude and practice study on biomedical waste management among health care professionals and paramedical students in a Tertiary Care Government Hospital in South India. Int. J. Environ. Health Engi., Vol. 2(5).

\section{How to cite this article:}

Shyamala, R., and Naveen, G. 2016. A Cross Sectional Study on Health Care Waste Management among Health Care Personnel in a Tertiary Care Center, Kannur, Kerala, India. Int.J.Curr.Microbiol.App.Sci. 5(9): 340-345. doi: http://dx.doi.org/10.20546/ijcmas.2016.509.037 